\title{
Racial Disparities in Preferences and Perceptions Regarding Organ Donation
}

\author{
Laura A. Siminoff, PhD, ${ }^{7}$ Christopher J. Burant, MACTM, MA, ${ }^{7}$ Said A. Ibrahim, MD, MPH ${ }^{2}$ \\ 'Department of Bioethics (TA-232), Case Western Reserve University, School of Medicine, Cleveland, OH, USA; ${ }^{2} \mathrm{Center}$ for Health Equity \\ Research and Promotion, University of Pittsburgh, VA Pittsburgh Healthcare System, Pittsburgh, PA, USA.
}

OBJECTIVES: To identify reasons for lower organ donation rates by African Americans, we examined knowledge and attitudes about brain death, donation, and transplantation and trust in the health care system.

METHODS: Data were collected from 1,283 subjects in Ohio using a random digit dial telephone survey. Items were developed based on focus group results. Willingness-to-donate indicators included a signed donor card and willingness to donate one's own and a loved one's organs.

RESULTS: Compared with whites, African-Americans had lower rates of signing a donor card (39.1\% vs $64.9 \%, P<.001)$, and willingness to donate their own organs $(72.6 \%$ vs $88.3 \%, P<.001)$ or a loved one's organs (53.0\% vs $66.2 \%, P<.001)$. African Americans had lower scores on the Trust in the Health Care System scale (mean scores $\pm \mathrm{SD}$, $9.43 \pm 3.05$ vs $9.93 \pm 2.88, P<.01$ ) and were more likely to agree that "if doctors know I am an organ donor, they won't try to save my life" (38.6\% vs $25.9 \%, P<.001)$, the rich or famous are more likely to get a transplant $(81.9 \%$ vs $75.7 \%, P<.05)$, and less likely to agree that doctors can be trusted to pronounce death $(68.2 \%$ vs $82.9, P<.001)$. African Americans were also more likely to agree that families should receive money for donating organs $(45.6 \%$ vs $28.0 \%, P<.001)$ and funeral expenses (63.1\% vs $46.6 \%, P<.001)$.

CONCLUSIONS: African Americans reported greater mistrust in the equity of the donation system and were more favorable about providing tangible benefits to donor families than white respondents.

KEY WORDS: decision making; disparities; minorities; organ donation; attitudes ; African Americans.

DOI: $10.1111 /$ j.1525-1497.2006.00516.x

J GEN INTERN MED 2006; 21:995-1000.

A frican Americans disproportionately have end-stage kidney disease, yet, they are less likely than whites to receive kidney transplantation. ${ }^{1}$ While $39 \%$ of people on the kidney waiting list are African American, only $23.0 \%$ of deceased donor organ recipients are African American. ${ }^{2}$ African Americans needing a kidney transplant wait, on average, 1,335 days, compared with 734 days for whites. ${ }^{3}$

Persons of color and those of lower educational, socioeconomic, and/or health status are less enthusiastic about organ donation $^{4-7}$ and less likely to sign a donor card or consent to a request for donation. ${ }^{8-11}$ Attitudinal surveys have reported that African Americans are less willing to donate their own or a family member's organs. ${ }^{12}$ More specifically, 1 large Gallup survey found that $72 \%$ of whites were very or somewhat likely to donate

None of the authors have any conflicts of interest to declare.

Address correspondence and requests for reprints to Dr. Siminoff: Department of Bioethics (TA-215), Case Western Reserve University, School of Medicine, 10900 Euclid Avenue, Cleveland, OH 44106-4976 (e-mail: las5@case.edu). their own organs, compared with $52 \%$ of African Americans. ${ }^{13}$ Another study found that only one-third of African Americans plan to be organ donors, compared with more than half of white respondents. ${ }^{10}$ A study of families making decisions about donation confirmed that African Americans are half as likely as whites to agree to donate a loved one's organs. ${ }^{14}$

It is not clear as to what factors influence African Americans' decisions about transplantation and donation. Lack of enthusiasm, negative attitudes toward donation, ${ }^{12,15}$ lack of awareness of the need for transplantable organs in the AfricanAmerican community, ${ }^{14}$ and mistrust of the health care system ${ }^{16-19}$ may all play a role. Therefore, we conducted a large probability survey of the general public to examine attitudes, perceptions, and knowledge regarding organ donation and transplantation and their relationship with decisions about organ donation.

\section{METHODS}

\section{Data and Sampling Frame}

The study was conducted in Ohio where residents' racial, age, educational, and economic characteristics are very similar to those of the U.S. population as a whole. ${ }^{20}$ Interviews of Ohio residents 18 years or older were conducted from June to August 2000. We obtained the residential random digit dial (RDD) sample frames from Genesys Sampling Systems (Fort Washington, PA), a commercial sampling firm. Genesys provides databases to conduct single-stage representative random digit dial surveys based on census tract Core-Based Statistical Areas. ${ }^{21}$ We randomly selected among adults in the household by selecting the adult who had most recently had a birthday. The participation rate was $60 \%$.

\section{Survey Development}

We first assembled a Community Advisory Board (CAB) and conducted a series of focus groups. The $\mathrm{CAB}$ included leaders of the state's majority and minority ethnic and religious communities and an advocate/leader for persons with disabilities. The $\mathrm{CAB}$ provided input into the survey content and language and helped to recruit focus group participants. A total of 12 focus groups were conducted with African Americans, Hispanics, Orthodox Jews, low-income white Catholics, fundamental Christians, Muslims, high income suburban whites, persons with disabilities, and rural residents. All groups were evenly composed of male and female respondents, except for gender-stratified groups

Manuscript received February 7, 2005

Initial editorial decision May 2, 2006

Final acceptance April 5, 2006 
for Muslim and Jewish participants. Two groups were conducted with African Americans, based on income. Each focus group included 8 to 12 members and lasted from 90 to 120 minutes.

Inputs from the $\mathrm{CAB}$ and focus groups were used to develop the final survey to assure that it reflected the communities' concerns and used language readily understood by a wide spectrum of the population. The final survey instrument took an average of 20 minutes to administer by telephone. IRB approval was obtained for the study. All focus group participants signed a consent form. Verbal consent was obtained from telephone survey respondents.

\section{Measures}

Dependent Variables. We assessed 3 indicators of willingness to donate: (1) having a signed donor card or checking the donor option on his/her driver's license, (2) stated willingness to donate their own organs, and (3) willingness to donate a loved one's organs after death. Responses were reported as yes or no.

Predictors. The primary predictor of interest was ethnicity (white vs African American). We also measured other sociodemographic characteristics including gender, education, income, age, and religiosity. Religiosity was measured using a modified version of Levin's Measurement of Religiosity scale ${ }^{22}$ that measures the importance and level of involvement in religion and spirituality. We developed measures of the other potentially important predictors: Trust in the Health Care System scale, questions concerning general attitudes toward organ donation, and a measure to determine knowledge about brain death and organ donation (Appendix A). Twelve items were drawn from surveys we had used with health care providers and families asked to donate organs. ${ }^{23}$

We assessed general attitudes toward organ donation by asking individuals to rate their agreement on the following 7 items using a 4-point Likert scale ranging from strongly agrees to strongly disagree: (1) presumed consent for organ donation; (2) payments to families who donate organs; (3) defraying funeral expenses for families who donate; (4) "first person consent" (i.e., binding consent for those on a donor registry); (5) designating the recipient(s) of the donated organs; (6) the rich or famous are more likely to get a transplant; and (7) doctors can be trusted to pronounce death correctly (Appendix A). We also asked who should receive priority for transplantation using 3 response options: the sickest, those most likely to be successful, or neither. We asked individuals to rate their agreement (4-point Likert scale ranging from strongly agree to strongly disagree) to the 4 items about "trust in the health care system" (Appendix A).

Five items assessed knowledge about organ donation and brain death (Appendix A). The first question asked whether subjects knew that a patient is on a respirator at the moment of organ removal. The second asked whether patients permanently on mechanical supports were either dead, alive, or could be either. The third assessed whether the subject knew that a brain-dead person could not hear. The fourth asked whether the subject knew that a brain-dead person is medically dead and, the fifth inquired whether the subject knew that in Ohio, brain-dead people are legally dead. Total scores ranged from 0 to 5 points.

Scale Development. We hypothesized that 2 constructs drove individuals' responses to the 12 attitude items: (1) general at- titudes toward organ donation and (2) trust in the health care system. We used exploratory factor analysis (EFA) with principal axis factoring, an oblimin rotation, and 2-factor extraction to evaluate our hypothesis. We also explored 1, 3, 4, and 5 factor solutions. Items were retained in a scale if the item had a primary factor loading of $>0.40$ and did not have a secondary factor loading $>0.30$. This indicated that an item had a strong relationship with only 1 factor or construct. A single-factor solution best fit our data and identified 4 items measuring trust in the health care system having factor loadings ranging from 0.43 to 0.77 and no secondary factor loadings $>0.30$. The Trust in the Health Care System scale was created by summing individuals' responses to each item. Cronbach's $\alpha$, a measure of reliability, was 0.70 , indicating that the scale had good internal consistency. Scale scores ranged from 4 to 16 , with higher scores reflecting greater trust in the health care system. ${ }^{14,22,23}$

The remaining 8 items measuring general attitudes toward organ donation did not load onto a single factor and may indicate that several discrete attitudes toward organ donation exist. These items were treated as 8 individual predictors.

\section{Analytic Strategies}

Descriptive statistics were generated for all items. Measures of association for ordinal and categorical data were assessed using the chi-square statistic, while $t$-tests assessed continuous variables. We compared the bivariate relationships between the primary predictor of interest-ethnicity (white vs African American)-and all other predictors and the 3 dependent variables. For the bivariate analyses, the independent variables were collapsed into 2 categories (agree vs disagree) from 4point Likert scales, but were used as 4-point Likert scales for the logistic regression analyses.

The multivariable logistic regressions performed were stratified by ethnicity, using sociodemographics, general attitudes toward organ donation, attitudes toward the health care system, and knowledge of brain death as predictors of the 3 donation decision outcomes. All predictors in the logistic regression were entered simultaneously (Appendix A). Predictor variables that were statistically significant $(P<.10)$ for at least 1 of the 3 outcomes were included in the final models. These variables were: (1) age; (2) education; (3) income; (4) knowledge of brain death (sum of the correct answers to 5 items); (5) Trust in the Health Care System scale; (6) the rich or famous are more likely to get a transplant; (7) when patients are eligible to donate organs, doctors can be trusted to pronounce death correctly; (8) law that everyone donates unless someone says no; (9) families should receive money for donating; (10) families who donate should be given money to pay for funeral expenses; (11) when someone has a donor card, hospitals do not need to ask the family's permission to donate the organs; and (12) families should be allowed to ask that donated organs go to a particular person. Predictors were entered simultaneously. We used the same set of predictors for all 3 final models, so we could compare these predictors across the 3 dependent variables of willingness to donate.

All significant predictors were treated as continuous for the final regression analyses. While education, income, and the items about attitudes toward organ donation (4-point Likert scale) were ordinal in nature, these were treated as continuous because they were normally distributed and had a wide 
Table 1. Sociodemographic Characteristics of the Overall Sample and by Race

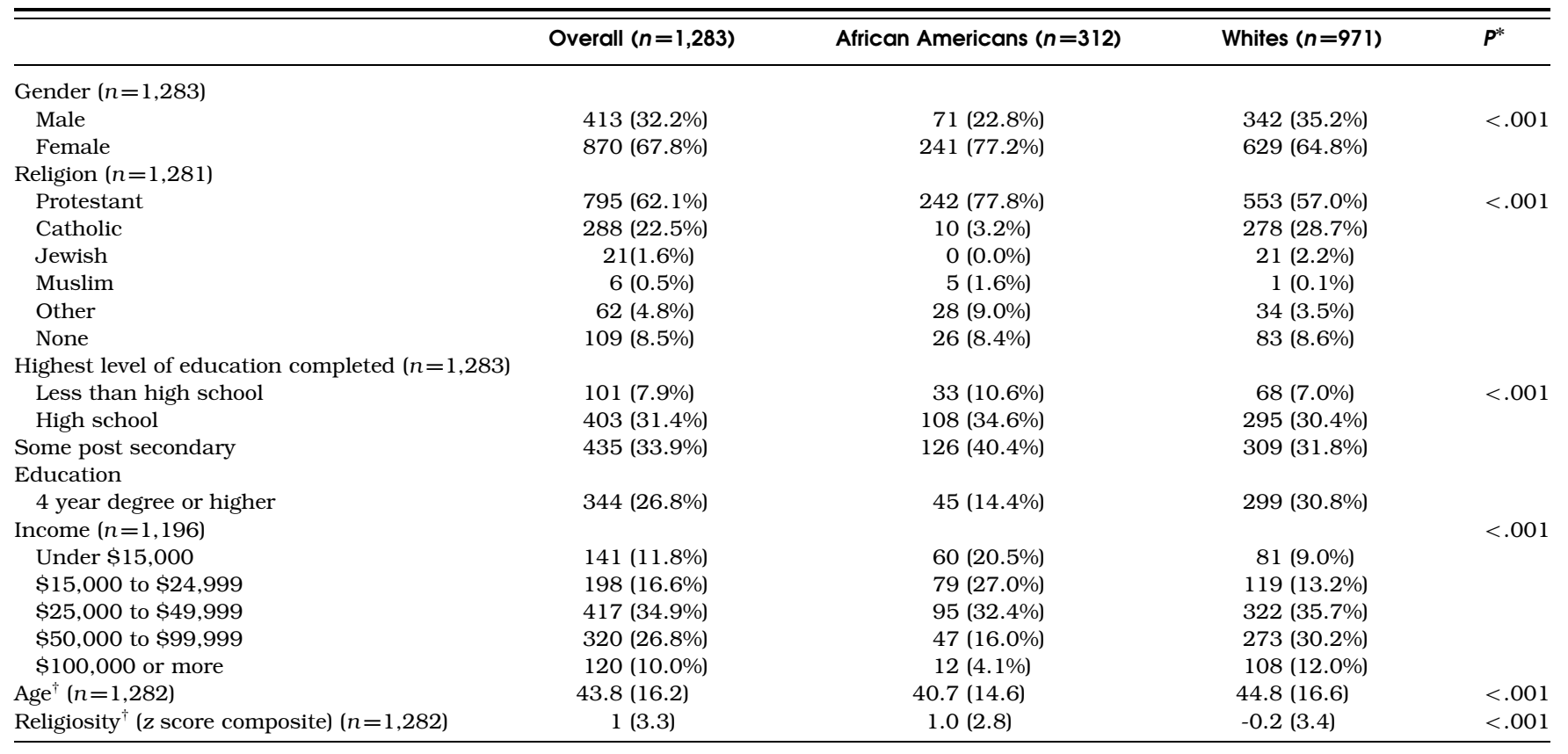

*Significance levels for 2-tail tests of the association between sociodemographic characteristics and race using a chi-squared test for categorical and $\mathrm{t}$-test for interval variables.

${ }^{\dagger}$ Mean (SD) value for factors measured on the interval scale.

range of variances. The categories used for education and income level are listed in Table 1. Data analysis was conducted using SPSS version 12 (Chicago, IL).

\section{RESULTS}

\section{Baseline Characteristics of the Sample}

The 1,283 white and African-American respondents (60\% participation rate) surveyed are included in these analyses. Table 1 summarizes the sample's sociodemographic characteristics. Briefly, compared with white respondents, African-American respondents were younger (mean age, 40.7 vs $44.8, P<.001$ ) and more likely to be women $(77.2 \%$ vs $64.8 \%, P<.001)$. White respondents were more likely to have a college education $(30.8 \%$ vs $14.4 \%, P<.001)$ and were more likely to have incomes in excess of $\$ 50,000(42.2 \%$ vs $20.1 \%, P<.001)$. African Americans were more likely to be Protestant $(77.8 \%$ vs $57.0 \%$, $P<.001)$ and reported higher levels of religiosity.

\section{Attitudes and Knowledge Related to Organ Donation}

Table 2 summarizes comparisons between white and AfricanAmerican respondents. Compared with whites, African Americans were more likely to favor benefits for organ donation, for example, families should be given money for donating $(45.6 \%$ vs $28.0 \%, P<.001)$ or provided money to pay for funerals (63.1\% vs $46.6 \%, P<.001)$. African Americans also had less trust in the health care system compared with whites. For example, they were less likely to agree that when patients are eligible to donate organs, doctors can be trusted to pronounce death correctly $(68.2 \%$ vs $82.9 \%, P<.001)$ and had lower scores on the trust in the health care system scale $(9.43 \pm 3.05$ vs $9.93 \pm 2.88, P<.01)$. Overall, whites scored higher than African-American respondents on a composite score of knowledge about brain death $(2.55 \pm 1.23$ vs $2.28 \pm$ 1.13, $P<.001)$.

Table 3 summarizes bivariate associations between our indicators of willingness to donate organs and ethnicity. African Americans, compared with whites, were less likely to: (1) have signed a donor card or other document (39.1\% vs $64.9 \%$, $P<.001)$; (2) donate their own organs after death $(72.6 \%$ vs $88.3 \%, P<001)$; and (3) donate a loved one's organs $(80.9 \%$ vs 93.1\%,P<.001).

\section{Multivariable Analyses of Predictors of Willingness to Donate}

Six logistic regressions examined the predictors of willingness to donate organs (Table 4). Among African American and white respondents alike, predictors of having a signed donor card included the following: younger age; higher educational level; being more likely to agree that there should be a law that everyone donates unless someone says no; and that for individuals with donor cards, hospitals do not need to ask the family's permission to donate the organs. Among African-American respondents, predictors of having a signed donor card included being (1) more likely to agree that the rich and famous are more likely to get a transplant and that families who donate should be given money to pay for funeral expenses and (2) less likely to agree that donor families should receive money. Among white respondents, predictors of having a signed donor card included: higher income levels, being more likely to trust the health care system, and agreeing that doctors can be trusted to pronounce death correctly.

African-American respondents had only 1 significant predictor of willingness to donate one's own organs (Table 4). African Americans were more likely to agree that there should be a law that everyone donates unless someone says no. Among white respondents, predictors of willingness to donate 
Table 2. Bivariate Associations Between Race, Attitudes, and Knowledge Related to Organ Donation

\begin{tabular}{|c|c|c|c|}
\hline & African Americans $(n=312)$ & Whites $(n=971)$ & $P^{*}$ \\
\hline \multicolumn{4}{|l|}{ General attitudes toward organ donation ${ }^{\dagger}$} \\
\hline Law that everyone donates unless someone says no (\% agreeing) & $125(40.2 \%)$ & $394(40.7 \%)$ & .86 \\
\hline Families should receive money for donating (\% agreeing) & $139(45.6 \%)$ & $269(28.0 \%)$ & $<.001$ \\
\hline Families who donate should be given money to pay for funeral expenses (\% agreeing) & $195(63.1 \%)$ & $447(46.6 \%)$ & $<.001$ \\
\hline $\begin{array}{l}\text { For someone with a donor card, hospitals do not need to ask the family's permission to } \\
\text { donate the organs (\% agreeing) }\end{array}$ & $210(68.0 \%)$ & $736(76.0 \%)$ & $<.01$ \\
\hline Families should be allowed to ask that donated organs go to a particular person (\% agreeing) & $139(45.0 \%)$ & $418(43.4 \%)$ & .62 \\
\hline Who should receive priority for transplant? & & & .001 \\
\hline Sickest & $174(56.9 \%)$ & $424(44.7 \%)$ & \\
\hline Most likely to be successful & $123(40.2 \%)$ & $501(52.8 \%)$ & \\
\hline Neither & $9(2.9 \%)$ & $24(2.5 \%)$ & \\
\hline \multicolumn{4}{|l|}{ Trust in the Health Care System } \\
\hline Health care system cares more about profits than people's health (\% agreeing) & $228(74.8 \%)$ & $695(73.1 \%)$ & .57 \\
\hline I do not trust the health care system (\% agreeing) & $148(47.9 \%)$ & $378(39.5 \%)$ & $<.01$ \\
\hline Health care system cares about my health as I do (\% agreeing) & $124(39.7 \%)$ & $352(36.6 \%)$ & .32 \\
\hline If doctors know I am an organ donor, they won't try to save my life (\% agreeing) & $118(38.6 \%)$ & $246(25.9 \%)$ & $<.001$ \\
\hline Trust in Health Care System Scale, Mean score $(+\mathrm{SD})^{\ddagger}$ & $9.43(3.05) \mathrm{b}$ & $9.93(2.88)$ & $<.01$ \\
\hline The rich or famous are more likely to get a transplant (\% agreeing) & $253(81.9 \%)$ & $721(75.7 \%)$ & $<.05$ \\
\hline $\begin{array}{l}\text { When patients are eligible to donate organs, doctors can be trusted to pronounce death } \\
\text { correctly (\% agreeing) }\end{array}$ & $208(68.2 \%)$ & $786(82.9 \%)$ & $<.001$ \\
\hline \multicolumn{4}{|l|}{ Knowledge } \\
\hline At the moment of organ removal are patients & & & $<.001$ \\
\hline On a respirator & $96(32.1 \%)$ & $430(47.3 \%)$ & \\
\hline Removed from a respirator & $203(67.9 \%)$ & $480(52.7 \%)$ & \\
\hline Patients permanently on life support & & & .10 \\
\hline Are dead & $71(23.7 \%)$ & $185(19.7 \%)$ & \\
\hline Are alive & $36(12.0 \%)$ & $154(16.4 \%)$ & \\
\hline Some are dead and some are alive & $193(64.3 \%)$ & $602(64.0 \%)$ & \\
\hline A brain-dead person can hear & & & $<.001$ \\
\hline No & $201(64.4 \%)$ & $726(74.8 \%)$ & \\
\hline Yes & $111(35.6 \%)$ & $245(25.2 \%)$ & \\
\hline A brain dead person is "dead," "as good as dead," or "alive" & & & $<.01$ \\
\hline Dead & $104(34.3 \%)$ & $408(42.8 \%)$ & \\
\hline As good as dead & $135(44.6 \%)$ & $409(42.9 \%)$ & \\
\hline Alive & $64(21.1 \%)$ & $136(14.3 \%)$ & \\
\hline According to Ohio, are people who are brain dead legally dead? & & & .10 \\
\hline No & $196(62.8 \%)$ & $659(67.9 \%)$ & \\
\hline Yes & $116(37.2 \%)$ & $312(32.1 \%)$ & \\
\hline $\begin{array}{l}\text { Total correct on the Assessment Tool for Knowledge of Brain Death-Range (0 to 5), Mean } \\
\text { score (+SD) }\end{array}$ & $2.28(1.13)$ & $2.55(1.23)$ & $<.001$ \\
\hline Have you heard of the term "brain death?" & & & $<.05$ \\
\hline No & $8(2.6 \%)$ & $10(1.0 \%)$ & \\
\hline Yes & $304(97.4 \%)$ & $961(99.0 \%)$ & \\
\hline
\end{tabular}

*Significance level for 2-tail tests of association between race and responses to attitude and knowledge items using a chi-square test.

$\dagger$ agreeing reflects individuals that responded either strongly agree or somewhat agree.

${ }^{\ddagger}$ Trust in Health Care System scale was scored by summing the 4 trust items. Item responses were based on a 4-point Likert scale ranging from strongly agree to strongly disagree. Scores ranged from 4 to 16 , with higher scores indicating a greater trust.

one's own organs included greater trust in the health care system; more knowledgeable about brain death; more likely to agree that doctors can be trusted to pronounce death correctly; and more likely to agree that there should be a law that everyone donates unless someone says no and that hospitals do not need to ask the family's permission to donate the organs if the patient has a donor card.

Among African-American respondents, predictors of agreeing to donate a loved one's organs were greater trust in the health care system and being less likely to agree that fam-

Table 3. Bivariate Associations Between Race and the 3 Indicators of Willingness to Donate Organs

\begin{tabular}{|c|c|c|c|}
\hline & African Americans $(n=312)$ & Whites $(n=971)$ & $P^{*}$ \\
\hline \multicolumn{4}{|l|}{ Indicator } \\
\hline $\begin{array}{l}\text { Do you have a signed donor card or checked the donor option on your } \\
\text { driver's license? (\% stating yes) }\end{array}$ & $122(39.1 \%)$ & $630(64.9 \%)$ & $<.001$ \\
\hline Would you be willing to donate your organs in the event of your death? (\% stating yes) & $207(72.6 \%)$ & $809(88.3 \%)$ & $<.001$ \\
\hline Would you be willing to donate a loved one's organ's after their death? & & & $<.001$ \\
\hline No & $57(19.1 \%)$ & $65(6.9 \%)$ & \\
\hline Yes, if I knew they wanted to & $83(27.9 \%)$ & $253(26.9 \%)$ & \\
\hline Yes & $158(53.0 \%)$ & $622(66.2 \%)$ & \\
\hline
\end{tabular}

*Significance level for a 2-tail test of the association between race and indicators of willingness to donate organs using a chi-square test. 
Table 4. Adjusted Odds Ratios and $95 \%$ Confidence Intervals of Willingness to Donate*

\begin{tabular}{|c|c|c|c|c|c|c|}
\hline & \multicolumn{2}{|l|}{ Signed Donor Card } & \multicolumn{2}{|c|}{ Donates Own Organs } & \multicolumn{2}{|c|}{ Donates Loved One's Organs } \\
\hline & $\begin{array}{l}\text { African } \\
\text { Americans }\end{array}$ & Whites & $\begin{array}{c}\text { African } \\
\text { Americans }\end{array}$ & Whites & $\begin{array}{l}\text { African } \\
\text { Americans }\end{array}$ & Whites \\
\hline \multicolumn{7}{|l|}{ Predictors } \\
\hline Age & $0.97(0.95$ to 0.994$)$ & $0.98(0.97-0.99)$ & NS & NS & NS & NS \\
\hline Education & $1.78(1.23$ to 2.58$)$ & $1.25(1.03$ to 1.51$)$ & NS & NS & NS & NS \\
\hline Income & NS & $1.26(1.07$ to 1.47$)$ & NS & NS & NS & NS \\
\hline Knowledge of brain death & NS & NS & NS & $1.32(1.08$ to 1.63$)$ & NS & NS \\
\hline Trust in Health Care System & NS & 1.07 (1.003 to 1.14$)$ & NS & $1.16(1.06$ to 1.27$)$ & $1.14(1.02$ to 1.29$)$ & NS \\
\hline $\begin{array}{l}\text { The rich or famous are more } \\
\text { likely to get a transplant }\end{array}$ & $1.51(1.12$ to 2.04$)$ & NS & NS & NS & NS & NS \\
\hline $\begin{array}{l}\text { When patients are eligible to } \\
\text { donate organs, doctors can be } \\
\text { trusted to pronounce death } \\
\text { correctly }\end{array}$ & NS & $1.40(1.13$ to 1.72$)$ & NS & $1.59(1.19$ to 2.14$)$ & NS & NS \\
\hline $\begin{array}{l}\text { Law that everyone donates } \\
\text { unless someone says no }\end{array}$ & $1.79(1.36$ to 2.35$)$ & $1.52(1.30$ to 1.78$)$ & $\begin{array}{l}2.03(1.45 \\
\text { to } 2.83)\end{array}$ & $\begin{array}{l}2.49(1.86 \\
\text { to } 3.34)\end{array}$ & NS & $\begin{array}{l}2.00(1.41 \\
\text { to } 2.84)\end{array}$ \\
\hline $\begin{array}{l}\text { Families should receive money } \\
\text { for donating }\end{array}$ & $0.73(0.54$ to 1.00$)$ & NS & NS & $\mathrm{NS}$ & NS & NS \\
\hline $\begin{array}{l}\text { Families who donate should be } \\
\text { given money to pay for funeral } \\
\text { expenses }\end{array}$ & $1.44(1.03$ to 2.01$)$ & NS & NS & NS & NS & NS \\
\hline $\begin{array}{l}\text { For someone with a donor card, } \\
\text { hospitals do not need to ask the } \\
\text { family's permission to donate } \\
\text { the organs }\end{array}$ & $2.06(1.54$ to 2.76$)$ & $1.20(1.03$ to 1.39$)$ & NS & $1.56(1.26$ to 1.92$)$ & NS & $\begin{array}{l}1.37(1.06 \\
\text { to } 1.78)\end{array}$ \\
\hline $\begin{array}{l}\text { Families should be allowed to } \\
\text { ask that donated organs go to a } \\
\text { particular person }\end{array}$ & NS & NS & NS & NS & $0.71(0.53$ to 0.94$)$ & NS \\
\hline
\end{tabular}

*All models controlled for age; education; income; knowledge of brain death; trust in health care system; the rich or famous are more likely to get a transplant; when patients are eligible to donate organs, doctors can be trusted to pronounce death correctly; law that everyone donates unless someone says no; families should receive money for funeral expenses; for someone with a donor card, hospitals do not need to ask the family's permission to donate the organs; families should be allowed to ask that donated organs go to a particular person. Predictors that were not significant included: (1) gender, (2) religiosity; (3) who should receive priority for transplantation. NS, not significant.

ilies should be allowed to donate organs to a particular person. Among white respondents, predictors of agreeing to donate a family member's organs included agreeing that there should be a law that everyone donates unless someone says no and being more likely to agree that hospitals do not need to ask the family's permission to donate the organs of patients with signed donor cards.

\section{DISCUSSION}

We conducted a large probability sample of the general public in order to examine hypotheses that whites and African Americans had different views about organ donation. We found that African Americans are less willing to donate their own or a family member's organs. They are half as likely to have signed a donor card and less likely to be willing to donate their own or a loved one's organs. Younger age and more education were independent predictors of whether an African-American respondent had a signed donor card. Religiosity played no role in predicting any of the donation outcomes for either ethnic group. Lastly, African Americans express greater concerns about the trustworthiness of the health care system, both in general and in terms of the donation system specifically, and were more likely to want to see the organs that they give go to other African Americans. These attitudes were independent predictors of having a signed donor card and being willing to donate one's own organs.
These results confirm pervious findings from other studies. For example, 1 large Gallup survey found that $72 \%$ of whites were very or somewhat likely to want to donate their own organs, while only $52 \%$ of African Americans felt this way. ${ }^{13}$ Another more recent survey found that only a third of African Americans plan to be organ donors, compared with more than half of whites. ${ }^{25}$ Others have also reported that awareness of transplantation in the African-American community was low in the 1980s. ${ }^{8,15}$ Reports show that African Americans are more likely than whites to believe that it is against their religion to donate ( $14 \%$ vs $3 \%$ ) and are also more likely to believe in the importance of being buried intact. ${ }^{13}$

Are African Americans less supportive of organ donation per se, or do the lower rates of donation reflect less interest in charitable activities? The latter seems unlikely because, in other aspects of life, African Americans of all socioeconomic levels are more likely to respond as volunteers or give to charities. ${ }^{26,27}$ This suggests that lower donor rates are probably not due to a lack of altruism.

We found that African Americans were quite supportive of incentives for donation, especially to help with funeral expenses for the donor. Regarding trust, other studies have found that African Americans are more likely to believe that health care professionals will not do as much to save their lives if they are designated organ donors and characterize the organ distribution system as unfair. ${ }^{13,24}$ Callender et al., ${ }^{18}$ in their work to promote organ donation in the African American community, 
has found a need for assurances that organs from African Americans would be given to African Americans.

These findings, collectively, indicate that the inequalities experienced by African Americans in their overall dealings with the health care system might negatively affect African Americans' willingness to donate organs. National efforts directed at improving overall trust in the health care system among African Americans will go a long way to improve organ donation and transplantation in African Americans.

This study has several limitations. Responses to projective questions are subject to a certain amount of inaccuracy, especially when they ask subjects to project responses to situations that are unfamiliar-such as a request for donation of a family member's organs. A certain amount of social desirability may have affected people's responses. Although the study was conducted in a single state, the sample size was designed so that the margin of error was small ( $\pm 4 \%$ ). In addition, the state of Ohio is generally representative of the United States, although the study did not include appreciable numbers of Hispanics or Asian Americans.

In summary, this is 1 of the largest studies comparing the attitudes and expressed willingness to donate organs of whites and African Americans. Its design was strengthened by the use of qualitative methods to structure the interview instrument. The results of the survey are striking for 2 reasons. Although African Americans are not as positive about organ donation as whites, the majority state that they would be willing to donate; this is in striking contrast to real donor rates that hover around $30 \% .^{28}$ The second finding of note is the pervasive mistrust in the health care system, including its equity. Until we address some of these issues, the rates of African American donation may continue to be low. Future studies should evaluate strategies to improve the trust of African Americans in the health care system in general and in the organ donation process in particular.

This project was funded by a grant R01-HS10047 from the Agency for Healthcare Research and Quality. Dr. Ibrahim is a recipient of a career development award from the VA Health Services Research and Development Office and the Robert Wood Johnson Foundation's Harold Amos Faculty Development Award.

\section{REFERENCES}

1. Sehgal AR, LeBeau So, Youngner SJ. Dialysis patient attitudes toward financial incentives for kidney donation. Am J Kidney Dis. 1997;29:410-8.

2. United Network for Organ Sharing. Critical Data: U.S. Facts about Transplantation. Richmond, VA: UNOS; 2004.

3. Nelson EW, Childress JE, Perryman J. Financial Incentives for Organ Donation: A Report of the UNOS Ethics Committee Payment Subcommittee. 1993. 1999 (United Network for Organ Sharing).

\section{Supplementary Material}

The following supplementary material is available for this article online at www.blackwell-synergy.com

\section{Appendix A. Scaled Items.}

4. Evans RW, Manninen DL. U.S. public opinion concerning the procurement and distribution of donor organs. Transpl Proc. 1988;20:781-5.

5. Robinette MA, Marshall WJ, Arbus GS, et al. The donation process. Transpl Proc. 1985;17(suppl 3):45-65.

6. Watt SM. How People Feel About Organ Donation. Great Neck, NY: Lieberman Research Inc; 1991.

7. The Partnership of Organ Donation, I. Solving the Organ Donor Shortage: A Report of the Partnership for Organ Donation. 1990.

8. Perez LM, Schulman B, Davis F, Olson L, Tellis VA, Malas AJ. Organ donation in three major American cities with large latino and black populations. Transplantation. 1988;46:553-7.

9. Ross SE, Nathan H, O'Malley KF. Impact of a required request law on vital organ procurement. J Trauma. 1990;30:820-4.

10. Sumrani N, Delaney V, Butt KM, Hong JH. The pattern of organ donation in a large urban center. NY State J Med. 1990;90:396-9.

11. Siminoff LA, Arnold RM, Caplan AL, Virnig BA, Seltzer DL. Public policy governing organ and tissue procurement in the united states: results from the national organ and tissue procurement study. Ann Intern Medi. 1995;123:10-7.

12. Hartwig MS, Hall G, Hathway D, Gaber O. Effect of organ donor race on health care team procurement efforts. Arch Surg. 1993;128:1331-5.

13. The Gallup Organization, I. The American Public's Attitude Toward Organ Donation and Transplantation. Boston, MA: The Partnership for Organ Donation; 1993.

14. Siminoff LA, Lawrence RH, Arnold RM. Comparison of black and white families' experiences and perceptions regarding organ donation requests. Crit Care Med. 2003;31:146-51.

15. Richard-Hughes S. Attitudes and beliefs of Afro-Americans related to organ and tissue donation. Int $J$ Trauma Nursing. 1997;3:119-23.

16. Siminoff LA, Arnold RM. Increasing organ donation in the AfricanAmerican community: altruism in the face of an untrustworthy system. Ann Intern Med. 1999; 130:607-9.

17. Koch T. They might as well be in Bolivia: race, ethnicity and the problem of solid organ donation. Theor Med Bioethics. 1999;20:563-75.

18. Callender CO, Hall LE, Yeager CL, Barber JB Jr., Dunston GM, PinnWiggins Vw. Organ donation and blacks: a critical frontier. $\mathrm{N}$ Engl J Med. 1991;325:442-4.

19. Gamble V. Under the shadow of tuskegee: African Americans and health care. Am J Public Health. 1997;87:1773-8.

20. U.S. Census Bureau. Profile of General Demographic Characteristics: 2000. Washington, DC: U.S. Census Bureau; 2000.

21. Genesys Sampling System. Available at: http://www.m-s-g.com/genesys/ genesyshme.htm.

22. Levin JS, Taylor RJ, Chatters LM. Multidimensional measure of religious involvement for African Americans. Soc Quart. 1995;36:157-73.

23. Siminoff LA, Gordon N, Hewlett J, Arnold RM. Factors influencing families' consent for donation of solid organs for transplantation. J Am Med Assoc. 2001;286:71-7.

24. Siminoff LA, Saunders Sturm CM. African-American reluctance to donate: beliefs and attitudes about organ donation and implications for policy. Kennedy Inst Ethics J. 2000;10:59-75.

25. National Kidney Foundation. Americans Recognize Organ Shortage, Support Animal to Human Transplants, New Survey Says. New York City, NY: National Kidney Foundation; 1998.

26. The Gallup Organization, I. Giving and Volunteering in the United States. Findings from a National Survey Conducted for Independent Sector. Washington, DC: Independent Sector; 1998.

27. Cohen SM, Kapsis RE. Participation of blacks, puerto ricans, and whites in voluntary associations: a test of current theories. Social Forces. 1978;56:1053-71.

28. United Network for Organ Sharing. Donors. Richmond, VA: UNOS; 2003. 